\title{
THERMOELECTRIC PROPERTIES OF DEPLETED URANIUM SELENIDES AND TELLURIDES
}

By Lindsay D. Norman, Jr.

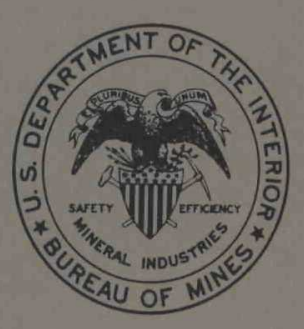

UNITED STATES DEPARTMENT OF THE INTERIOR BUREAU OF MINES 1965 


\section{DISCLAIMER}

This report was prepared as an account of work sponsored by an agency of the United States Government. Neither the United States Government nor any agency Thereof, nor any of their employees, makes any warranty, express or implied, or assumes any legal liability or responsibility for the accuracy, completeness, or usefulness of any information, apparatus, product, or process disclosed, or represents that its use would not infringe privately owned rights. Reference herein to any specific commercial product, process, or service by trade name, trademark, manufacturer, or otherwise does not necessarily constitute or imply its endorsement, recommendation, or favoring by the United States Government or any agency thereof. The views and opinions of authors expressed herein do not necessarily state or reflect those of the United States Government or any agency thereof. 


\section{DISCLAIMER}

Portions of this document may be illegible in electronic image products. Images are produced from the best available original document. 


\section{THERMOELECTRIC PROPERTIES \\ OF DEPLETED URANIUM SELENIDES AND TELLURIDES}

By Lindsay D. Norman, Jr.

* * * * * * * * * * report of investigations 6638

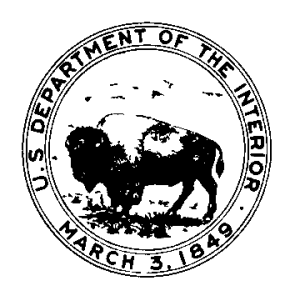

UNITED STATES DEPARTMENT OF THE INTERIOR BUREAU OF MINES 
This publication has been cataloged as follows:

\section{Norman, Lindsay D}

Thermoelectric properties of depleted uranium selenides and tellurides, by Lindsay D. Norman, Jr. [Washington] U.S. Dept. of the Interior, Bureau of Mines [1965]

18 p. illus., tables. (U. S. Bureau of Mines. Report of investigations 6638)

Includes bibliography.

1. Uranium selenides. 2. Tellurides. I. Title. (Series)

TN23.U7 no. $6638 \quad 622.06173$

U. S. Dept. of the Int. Library 


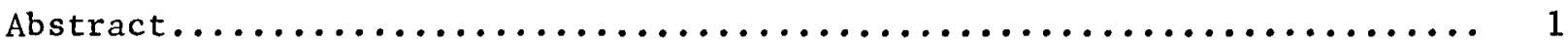

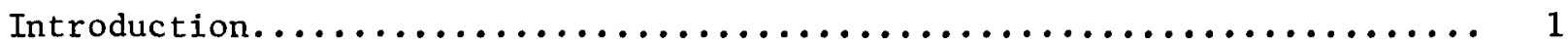

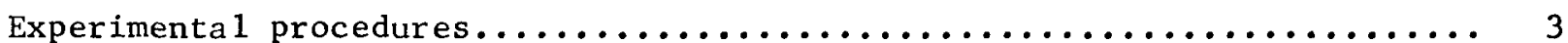

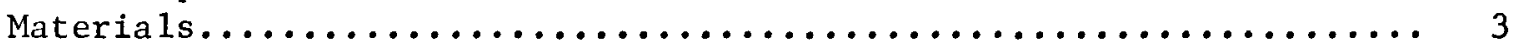

Sample preparation and fabrication..................... 3

Sample ana lysis and characterization.................... 6

Thermoelectric evaluation........................... 8

Discussion of results................................ 10

Undoped uranium cha 1 cogenides ......................... 10

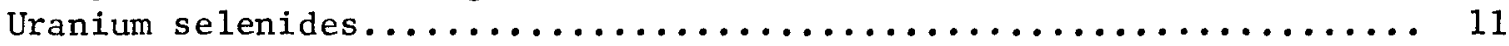

Uranium tellurides.................................. 14

Doped uranium monocha lcogenides...................... 15

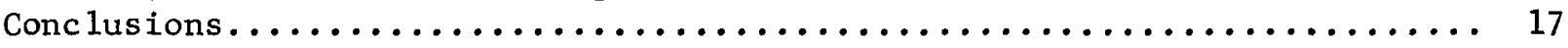

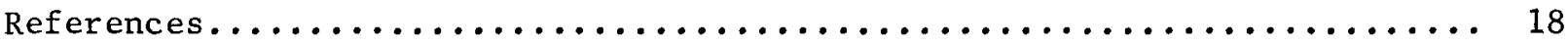

ILLUSTRATIONS

Fig.

1. Uranium processing equipment........................ 6

2. Hot-press die assembly............................ 7

3. Sample holder for electrical measurements................ 8

4. Electrical measurement circuit......................... 9

5. Absolute Seebeck coefficient of the uranium selenides.......... 12

6. Electrical resistivity of the uranium selenides............... 12

7. Absolute Seebeck coefficient and electrical resistivity of

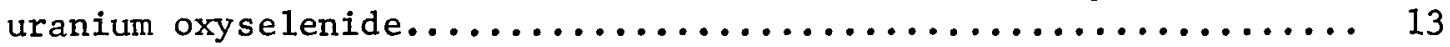

8. Absolute Seebeck coefficient of the uranium tellurides......... 15

9. Electrical resistivity of the uranium tellurides.............. 16

\section{TABLES}

1. Spectrographic analyses of the uranium and chalcogen starting materials................................... 4

2. Spectrographic analyses of doping materials................

3. Analyses and sample fabrication data of undoped uranium chalcogenides............................... 


\title{
THERMOELECTRIC PROPERTIES OF DEPLETED URANIUM SELENIDES AND TELLURIDES
}

\author{
by
}

Lindsay D. Norman, Jr. 1

\begin{abstract}
Thermoelectric properties of depleted uranium selenides and tellurides were investigated from room temperature to $700^{\circ} \mathrm{C}$. Severa 1 depleted uranium monoselenides and monotellurides were doped with selected cationic and anionic materials to determine the effect of impurity additions on the thermoelectric properties.

The undoped uranium selenides and tellurides were semimetallic conductors exhibiting low Seebeck coefficients and electrical resistivities. Partial or complete degeneracy was in evidence, indicating a charge carrier energy distribution similar to that in a metal. Doping increased the Seebeck coefficients of the uranium monoselenides and monotellurides; however, the corresponding change in the power factor in the figure of merit was small because of the increase in electrical resistivity.
\end{abstract}

\section{INTRODUCTION}

The first nuclear reactors employed natural uranium fuel containing 99.28 percent of the isotope U238. Since the development of the gaseous diffusion process in which the naturally occurring fissionable isotope U235 is separated from U238, reactors using fuel enriched in U235 have become increasingly popular, especially in non-military installations. A byproduct of the separation, depleted uranium, contains less U235 than natural uranium and has been accumulating in significant quantities as tails from the gaseous diffusion plants. Only a small fraction of the growing stockpile of depleted uranium is utilized in plutonium breeder reactors, reactor shields, and other nuclear applications. Although various non-nuclear uses for depleted uranium have been proposed, it appears likely that consumption of this material will not exceed a few hundred tons over the next 5 years even if all the potential markets were exploited. Because none of the potential uses are expected to substantially alter the

${ }_{1}$ Research physical meta1lurgist, College Park Metallurgy Research Center, Bureau of Mines, College Park, Md.

Work on manuscript completed October 1964. 
present uranium economy, finding additional uses for depleted uranium remains a challenging technological problem.

Semiconductor materials research in the last two decades indicated that uranium and other high-atomic-number elements might be candidates for use in thermoelectric semiconductor devices. Many metal combinations including some containing uranium are known to exhibit semiconducting properties in various degrees. A few of these materials are in commercial use and others indicate a great potential for further development. One deterrent to more progress in thermoelectric science is the lack of any theoretical or empirical means for predicting the most efficient metal combinations or for estimating the magnitude of their respective thermoelectric parameters. Therefore, the best materials must still be found largely by a systematic process of elimination. Inasmuch as the Bureau of Mines was conducting other investigations of thermoelectric materials, a research project was initiated in 1961 under a cooperative agreement between the Bureau and the Atomic Energy Commission to determine whether certain depleted uranium compounds would have electrical properties suitable for thermoelectric applications.

For a material to qualify as a useful thermoelectric material for power generation or refrigeration devices, it must ordinarily meet criteria such as a high Seebeck coefficient, low electrical resistivity, and low therma 1 conductivity to reduce heat transfer $(\underline{5}, \underline{8}, \underline{9}) .{ }^{2}$ These parameters are combined into a single term, the figure of merit $(\bar{z})$, which indicates the usefulness of a material for thermoelectric applications. The figure of merit is given by :

$$
z=\alpha^{2} / \rho \mathrm{k},{ }^{\circ} \mathrm{c}^{-1}
$$

where $\alpha$ is the Seebeck coefficient; $\rho$, the electrical resistivity; and $k$, the thermal conductivity. Commercial thermoelectrics generally have figures of merit of $10^{-3} \cdot \mathrm{C}^{-1}$.

Because thermal conductivities are difficult to obtain and not widely different among similar materials, the power factor, $\alpha^{2} / \rho$, is frequently used in initial assessments of thermoelectric properties. In genera $1, \alpha^{2} / \rho$ values greater than $10^{-5}$ watts $/ \mathrm{cm}^{\circ} \mathrm{C}^{2}$ indicate a figure of merit greater than $10^{-4}{ }^{\circ} \mathrm{C}^{-1}$. When the power factor is below this value, thermal conductivity measurements are often omitted because it is unlikely that a worthwhile figure of merit would result.

Aside from technical aspects that determine thermoelectric potential of a material, depleted uranium satisfies the economic requirements of availability and low cost. This is in contrast to many of the presently accepted thermoelectric materials that are relatively expensive because of their scarcity. Other factors favoring the use of uranium for thermoelectric applications are its high atomic weight and the high melting points of most of its compounds. The lattice thermal conductivity usually decreases with increasing mean atomic

\footnotetext{
"Underlined numbers in parenthesis refer to items in the references at the end of the report.
} 
weight for similar compounds of a series. High melting points usually ind1cate separation of the energy bands over larger temperature ranges, thus increasing the operable range of high-melting thermoelectric compounds. Some uranium compounds are reported (6) to exhibit a degree of covalent bonding and thus may have some separation of the energy bands. These include compounds of uranium with the Group Va and VIa elements. Efforts were therefore begun on the thermoelectric evaluation of these materials with initial emphasis on the selenides and tellurides. In the broad sense the term chalcogenide refers to binary compounds containing oxygen, sulfur, selenium, tellurium or polonium; in this report the term is restricted to the selenium and tellurium compounds.

Review of the technical literature revealed that several researchers $(1,10,12,14)$ had previously or were currently studying the thermoelectric behavior of several rare earth compounds including the uranium chalcogenides. The reported data, however, were widely conflicting mainly because of the apparent difficulties encountered in obtaining accurate materials analyses and reproducible compositions. These uncertainties indicated the need for further study of the thermoelectric properties of the uranium chalcogenides. In addition, doping experiments with selected cationic and anionic materials were needed to determine the effect of impurity additions on the thermoelectric parameters.

\section{EXPERTMENTAL PROCEDURES}

\section{Materia 1s}

Although thermoelectric materials often contain 1 percent or more added impurities, the starting materials are usually of high purity and the impurity level is closely controlled during processing to produce the optimum thermoelectric properties. The materials used in this investigation were of the highest purity available. The depleted uranium, produced by molten salt electrorefining in an $\mathrm{NaCl}_{-} \mathrm{UCl}_{3}$ electrolyte, was supplied by the Boulder City Metallurgy Research Laboratory of the Bureau and represented six different refining runs. The uranium ${ }^{3}$ was analyzed spectrographically as $99.9+$ percent pure, by difference. The selenium and tellurium used in compounding the chalcogenides were obtained commercially and were high-purity semiconductor grade analyzing 99.999+ percent pure, by difference. The spectrographic ana1yses of the uranium and chalcogens are given in table 1 and of the doping materials in table 2 .

\section{Sample Preparation and Fabrication}

The reactivity and pyrophoric nature of uranium and its compounds required extreme precautions during the preparation of the experimental materials. Argon glove boxes, used for all handling and preparatory steps, proved successful in minimizing contamination.

The uranium hydride reaction $(\underline{3}, \underline{4})$ was used to produce highly reactive uranium metal powder from chunks or turnings of uranium meta 1 . Figure 1

\footnotetext{
"Uranium hereafter denotes "depleted uranium" unless otherwise noted.
} 
diagrams the equipment in which uranium hydride, $\mathrm{UH}_{a}$, was produced by the reaction of purified hydrogen with cleaned uranium metal at $225^{\circ} \mathrm{C}$. Chunks or turnings of uranium metal at $500^{\circ} \mathrm{C}$ were used as the getter. The $\mathrm{UH}_{3}$ powder was decomposed to uranium metal by raising the temperature to $450^{\circ} \mathrm{C}$ and reducing the pressure to $0.001 \mathrm{~mm} \mathrm{Hg}$ or less. The resulting uranium powder contained less than 0.1 percent impurity. The chalcogens and doping agents were heated to $200^{\circ} \mathrm{C}$ in a vacuum of $0.01 \mathrm{~mm} \mathrm{Hg}$ or less to remove water and other volatile gases before reacting with the uranium.

TABLE 1. - Spectrographic analyses of the uranium and chalcogen starting materials

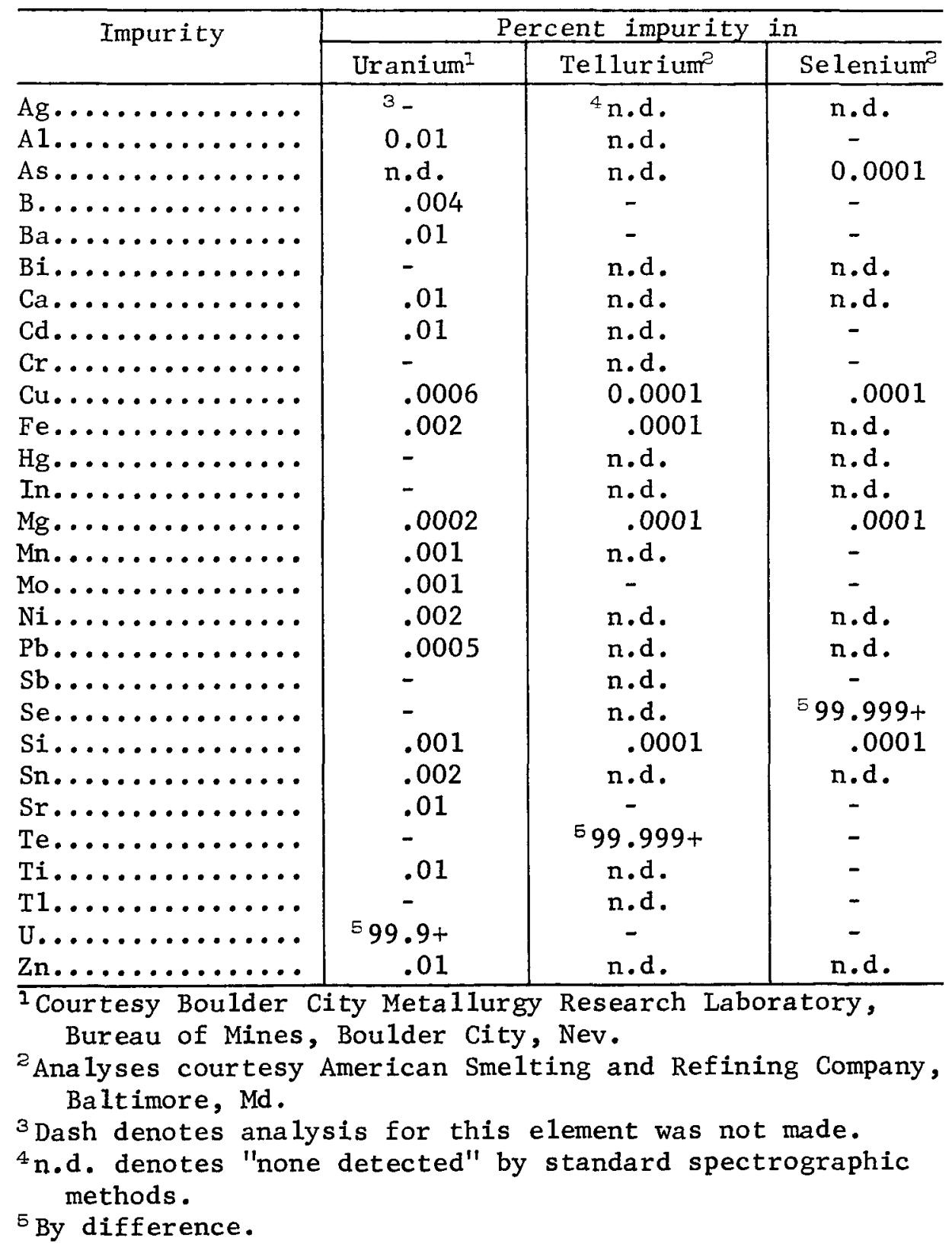


TABLE 2. - Spectrographic analyses of doping materials 1

\begin{tabular}{|c|c|c|c|c|c|c|}
\hline \multirow[t]{2}{*}{ Impurity } & \multicolumn{6}{|c|}{ Percent impurity in } \\
\hline & Antimony & Arsenic & Bismuth & Indium & Tha 11ium & Zinc \\
\hline$g \ldots .$. & ${ }^{2}$ n.d. & n.d. & 0.0002 & n.d. & n.d. & 0.0001 \\
\hline$\ldots \ldots \ldots$ & n.d. & n.d. & n.d. & n.d. & n.d. & n.d. \\
\hline$s \ldots \ldots \ldots \ldots$ & 0.005 & $499.999+$ & $3-$ & n.d. & - & - \\
\hline$\ldots \ldots$ & .0001 & n.d. & $499.999+$ & n.d. & $\mathrm{n} \cdot \mathrm{d}$. & $\mathrm{n} \cdot \mathrm{d}$. \\
\hline Cd...... & $\mathrm{n} \cdot \mathrm{d}$. & n.d. & n.d. & 0.0001 & n.d. & .0001 \\
\hline $\mathrm{Cr} \ldots \ldots$ & $\mathrm{n} \cdot \mathrm{d}$. & n.d. & n.d. & - & n.d. & $\mathrm{n} \cdot \mathrm{d}$. \\
\hline$\ldots \ldots$ & .0002 & .0001 & .0001 & .00005 & 0.005 & .0001 \\
\hline $\mathrm{Fe} \ldots .$. & .0005 & $\mathrm{n} \cdot \mathrm{d}$ & .0001 & .0001 & .0001 & .0001 \\
\hline In $\ldots \ldots$ & n.d. & n.d. & n.d. & ${ }^{4} 99.999+$ & $\mathrm{n} \cdot \mathrm{d}$. & $\mathrm{n} . \mathrm{d}$. \\
\hline $\mathrm{Mg} \ldots .$. & .0001 & .0005 & .0001 & - & .0001 & .0001 \\
\hline $\mathrm{Mn} \ldots .$. & $\mathrm{n} \cdot \mathrm{d}$ & n.d. & $\mathrm{n} \cdot \mathrm{d}$ & $\mathrm{n} \cdot \mathrm{d}$. & $\mathrm{n} \cdot \mathrm{d}$ & $\mathrm{n} \cdot \mathrm{d}$ \\
\hline $\mathrm{Ni} \ldots .$. & n.d. & n.d. & $\mathrm{n} \cdot \mathrm{d}$ & n.d. & n.d. & n.d. \\
\hline $\mathrm{Pb} \ldots$ & .0005 & n.d. & .0003 & .0001 & .007 & .0001 \\
\hline $\mathrm{Sb} \ldots .$. & ${ }^{4} 99.99+$ & n.d. & n.d. & $\mathrm{n} . \mathrm{d}$ & n.d. & n.d. \\
\hline Si..... & .0001 & n.d. & .0001 & - & n.d. & .0001 \\
\hline Sn . . . . & $\mathrm{n} . \mathrm{d}$ & n.d. & n.d. & .0001 & n.d. & $\mathrm{n} \cdot \mathrm{d}$ \\
\hline Te...... & $\mathrm{n} \cdot \mathrm{d}$ & n.d. & - & $\mathrm{n} \cdot \mathrm{d}$ & - & - \\
\hline $\mathrm{T} 1 \ldots$ & .0001 & n.d. & $\mathrm{n} \cdot \mathrm{d}$. & $\mathrm{n} . \mathrm{d}$. & $499.95+$ & $\mathrm{n} . \mathrm{d}$ \\
\hline $\mathrm{Zn} \ldots \ldots$ & n.d. & n.d. & n.d. & n.d. & n.d. & ${ }^{4} 99.999+$ \\
\hline
\end{tabular}

${ }^{1}$ Analyses courtesy American Smelting and Refining Company, Baltimore, Md.

${ }^{2}$ n.d. denotes "none detected" by standard spectrographic methods.

${ }^{3}$ Dash denotes analysis for this element was not made.

${ }^{4}$ By difference.

In preparing the uranium chalcogenides, weighed quantities of uranium powder and chalcogen were placed in a two-compartment quartz ampoule so that the respective elements were separated. The loaded ampoule was evacuated to $0.001 \mathrm{~mm} \mathrm{Hg}$, sealed with an oxygen-hydrogen torch, and transferred to a tube furnace where a programed temperature cycle was begun. At the initial soaking temperature, the chalcogen slowly volatilized and diffused to the uranium to react at a rate determined by the volatilization rate. After the initial reaction, the ampoule was cooled, its contents were ground to minus 250-mesh in the glove box and then resealed in another ampoule. The ampoule was then heated to the final soaking temperature and held for 100 to $150 \mathrm{hr}$ so that the product was homogenized. The initial soaking temperatures for the selenides and tellurides were $400^{\circ} \mathrm{C}$ and $600^{\circ} \mathrm{C}$, respectively, and the final soaking temperature was $1,000^{\circ} \mathrm{C}$. Upon completion of the heating cycle, the chalcogenide was removed from the ampoule and the product, and any residues were weighed in the glove box to determine the change in nominal composition of the material.

The doped uranium chalcogenides were prepared by essentially the same technique as that used for the undoped compounds. The doping material was placed in either the uranium or chalcogen compartment of the ampoule depending on the volatility of the doping material. Dopants relatively volatile at the reaction temperature were intermixed with the chalcogen and diffused with it 


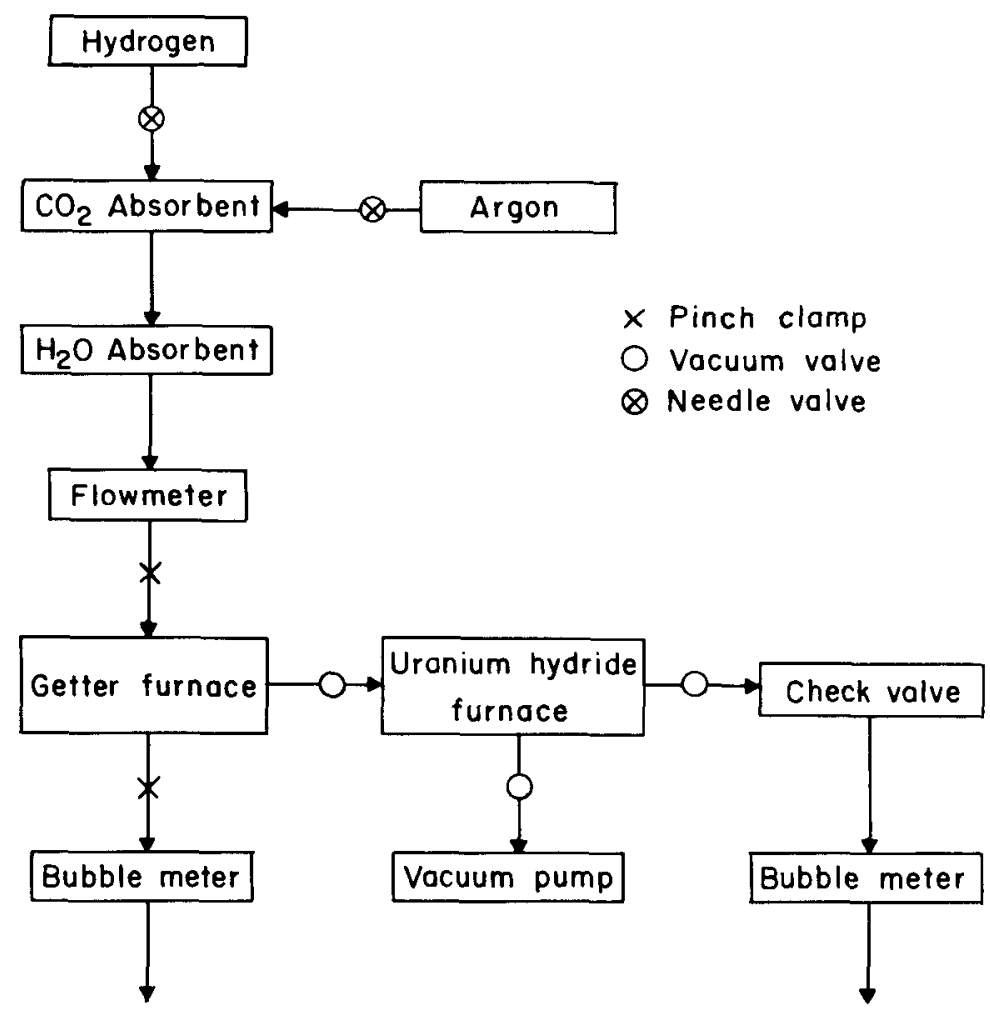

FIGURE 1. - Uranium Processing Equipment. to the uranium compartment. Elements with low volatilities were ground and dispersed throughout the uranium powder prior to sealing the ampoule.

The chalcogenide powders were hot pressed into dense rods approximately $1 \mathrm{~cm}$ diameter and $2 \mathrm{~cm}$ long for the thermoelectric property measurements. The powders were weighed and carefully loaded into the lined graphite die illustrated in figure 2. The die and rams were dense, highpurity graphite. The sample and die assembly were induction heated with a highfrequency generator. A Chrome1-Alume $1^{4}$ thermocouple in the lower ram measured the temperature of the sample during pressing. Measured temperatures were $\pm 1^{\circ} \mathrm{C}$ of the actural sample temperature. Tantalum sleeves were inserted between the sample and graphite parts of the die to prevent carbon contamination. The graphite sleeve was used to prevent the sample from binding in the die after densification at high pressures and temperatures. All gaskets and 0 -rings were silicone rubber and the entire assembly was operated in a purified argon atmosphere. A hydraulic press was used for pressing. When the desired pressure on the die was reached, the temperature was rapidly increased to $900^{\circ}$ to $1,200^{\circ} \mathrm{C}$ and held for 20 to $40 \mathrm{~min}$. After the pressing operation, the sample was pressed from the die and transferred back to the glove box.

\section{Sample Analysis and Characterization}

Nominal compositions of the experimental compounds were calculated from the initial weights of the uranium and chalcogen. It was assumed that any weight losses during the reaction period were attributable to free uranium reacting with the surface of the quartz ampoules. Weight losses during the pressing operation were the result of chalcogen vaporization at the pressing temperature and usually did not exceed 1 percent of the total sample weight. The final composition of the uranium compounds after hot pressing was determined by X-ray diffraction and electron-probe microanalysis. The calculated composition, when corrected for losses during the reaction and pressing

${ }^{4}$ Reference to specific trade names is made to facilitate understanding and does not imply endorsement of such brands by the Bureau of Mines. 


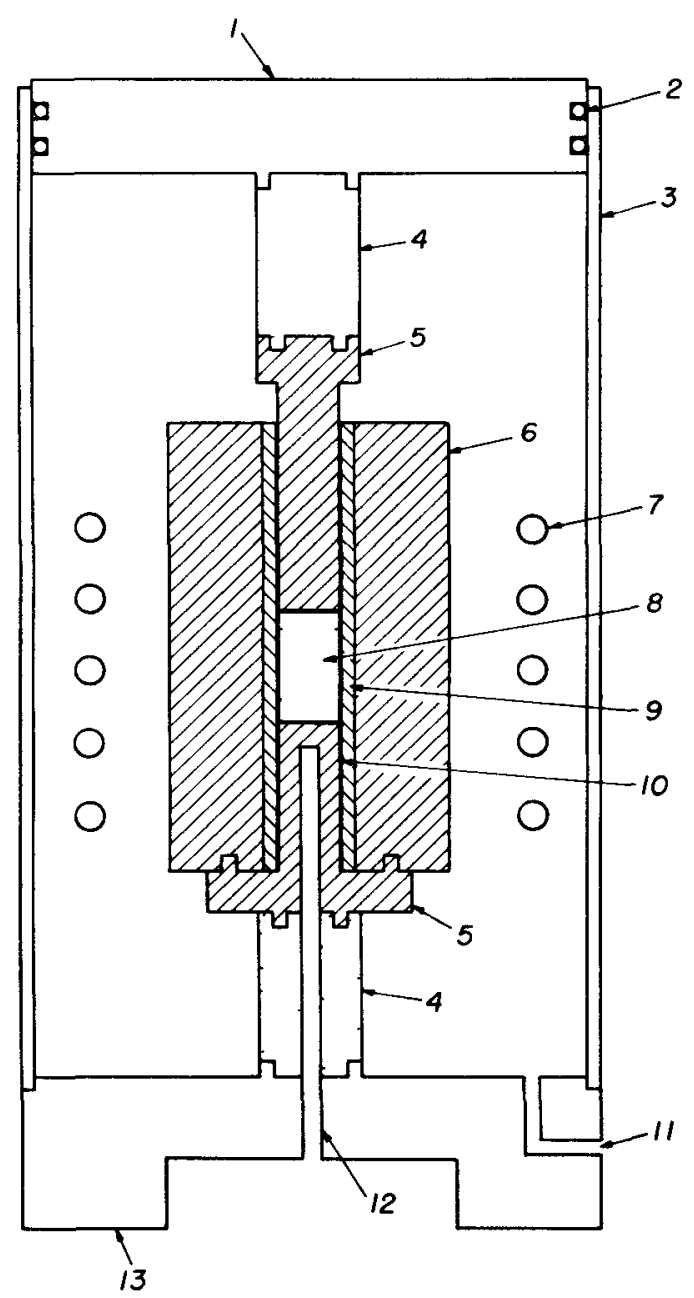

operations, was generally within 10 percent of that found by analysis. The powder method devised by Debye and Scherrer was used for a 11 X-ray diffraction identifications.

Results of the diffraction analysis were indexed and actua 1 compositions were determined when published diffraction data ( $\underline{6}, \underline{7}$, $11, \underline{13}, 14$ ) were avai 1 ble. Theoretical densities were calculated from the X-ray cell data and were compared with both the measured value and those values found in the literature to determine the percent of theoretical density of the experimenta 1 compounds. In several of the patterns, line intensities did not agree with published data, lines listed by others were missing or were shifted, or additiona 1 lines appeared.

FIGURE 2. - Hot-Press Die Assembly.

If no published data existed for a particular compound or if it could not be identified, the actual composition was usually determined with the aid of electron-probe microanalyses. After sectioning and polishing the test samples, approximately 10 to 15 determinations were made on random sections of each sample. The element concentrations were reported accurate to less than 2 percent of the amount present. The construction and operation of electronprobe $X$-ray spectrographs are described in the literature ( 2 ).

In genera1, the combined use of X-ray diffraction and electron-probe analyses produced fairly accurate material identifications of most of the compounds studied. Although the indexed compound and that calculated from the element concentrations generally agreed, the two techniques occasionally gave different results for a particular material. In these cases, additional electron-probe microanalyses were made, and metallographic specimens were prepared to determine the homogeneity of the particular sample. Because most of the materials were found to be very nearly single phase, the X-ray diffraction patterns for these specimens were assumed characteristic of the composition calculated from the electron-probe analyses. 


\section{Thermoelectric Evaluation}

Electrical measurements were taken from room temperature to $700^{\circ} \mathrm{C}$ in the sample holder illustrated in figure 3. The sample was held between two copper electrodes that extended through alumina insulating disks. Inconel rods provided structural support between the alumina disks. A copper current lead and Chrome1-Alumel thermocouple were attached to each electrode, and the heater consisted of Chromel $\mathrm{P}$ wire. The sample holder was contained in a Vycor tube which was nested in a 3-zone tube furnace controlled by a time-proportioning program controller. The thermocouples, current, and resistivity probe leads were run through ceramic insulators to the end of the tube where they passed through vacuum, multiterminal headers to the measuring equipment shown schematically in figure 4.

The techniques that were used to measure the Seebeck coefficient and electrical resistivity were similar to various equipment designs found in the literature $(\underline{5}, \underline{8})$.

An estimate of the error involved in measuring Seebeck voltages and electrical resistivities in this investigation was obtained by comparing the known thermoelectric properties of several $\mathrm{n}$ - and $\mathrm{p}$-type lead telluride thermoelements with those measured for the same material. Over most of the temperature ranges studied, the experimental measurements were within 10 percent of the known values. The major sources of error arose from difficulties encountered in obtaining temperature equilibrium across the sample and reducing contact resistance between the copper electrodes and sample end faces.

Data needed to calculate electrical resistivity were taken by sending a square-wave alternating current through the sample and standard resistor shown in figure 4. Alternating instead of direct current was used to avoid Peltier heating in the sample. The current, I, was calculated from the voltage drop $V_{R s}$, across the standard resistor measured by converting the square-wave alternating-current voltages to pulsating direct current and balancing these

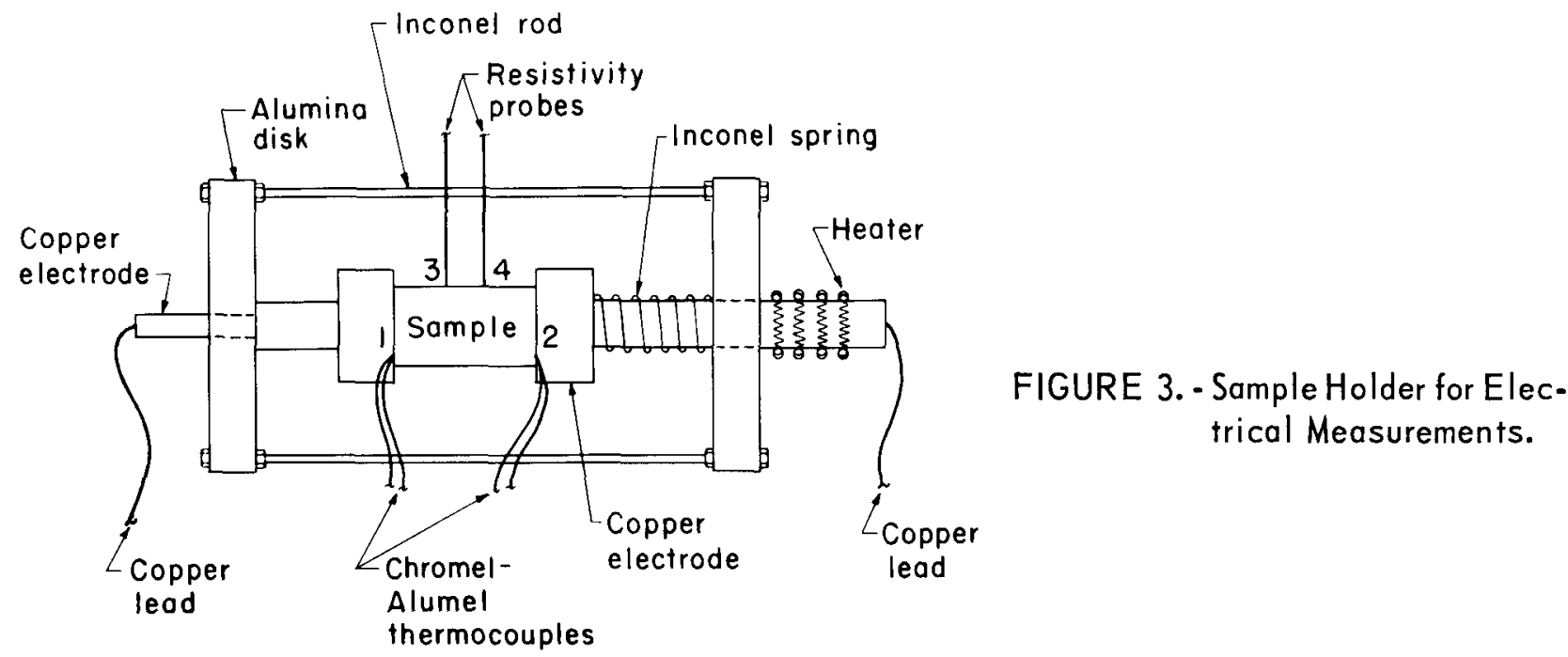




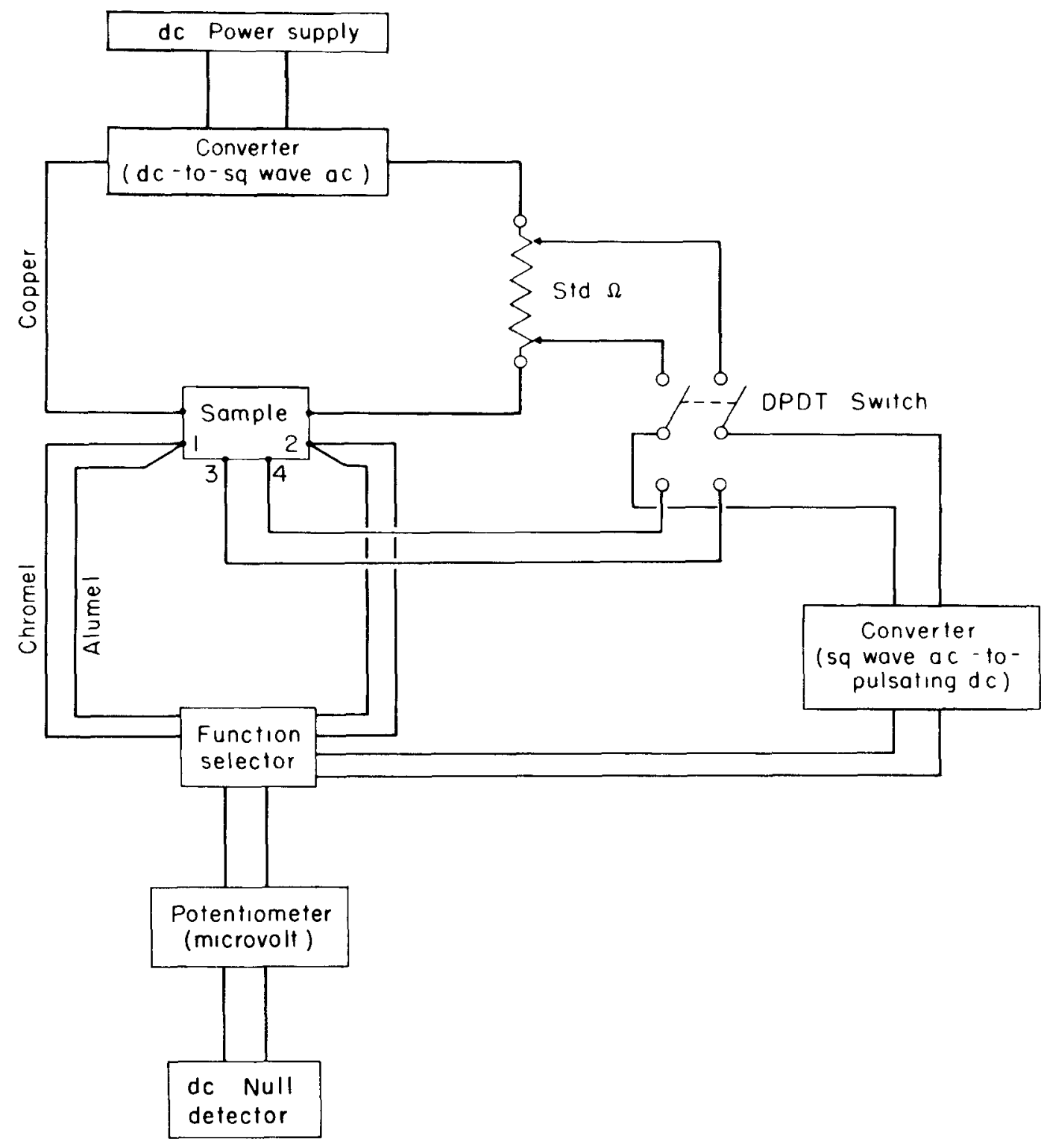

FIGURE 4. - Electrical Measurement Circuit.

on the direct-current potentiometer. $V \rho$, the voltage drop across the resistivity probes $\left(V_{4}-V_{3}\right)$, was measured in a like manner. The electrical resistivity was given by:

$$
\rho=\frac{V \rho}{I} \times \frac{A}{L}, \text { ohm }-c m
$$

where $A$ and $L$ are the cross sectional area and the distance between probes in centimeters respectively, on the sample. V $\rho$ was purely resistive, providing no temperature gradient was present across the sample. Once temperature 
equilibrium had been established across the sample, switching the DPDT switch allowed rapid measurements of $V_{R s}$ and $V \rho$ with the potentiometer.

Seebeck voltage, $V \alpha$, was measured by disconnecting the current source from the electrodes and sending up to $1.5 \mathrm{amp}$ through the electrode heater winding shown in figure 3. When a temperature gradient of $5^{\circ}$ to $10^{\circ} \mathrm{C}$ was produced across the sample, and $\mathrm{T}_{1}$ and $\mathrm{T}_{2}$ were constant, $\mathrm{V} \alpha$ was measured across either the Chromel or Alumel legs of the thermocouples attached to each electrode. The absolute Seebeck coefficient of the sample, $\alpha_{s}$, was calculated from:

$$
\alpha_{s}=\frac{ \pm V \alpha(\mathrm{Chr})}{\Delta \mathrm{T}}+\alpha(\mathrm{Chr})=\frac{ \pm \mathrm{V} \alpha(\mathrm{Alu})}{\Delta \mathrm{T}}+\alpha(\mathrm{Alu}), \mu \mathrm{V} /{ }^{\circ} \mathrm{C}
$$

where $\alpha(\mathrm{Chr})$ and $\alpha(\mathrm{Alu})$ are the absolute Seebeck coefficients of Chromel and Alume1, respectively.

\section{DISCUSSION OF RESULTS}

\section{Undoped Uranium Chalcogenides}

Early in this investigation several uranium selenide and uranium telluride materials were prepared to determine the optimum hot-pressing conditions for producing high-density materials. Chalcogenides with similar particle size and composition were hot pressed at various times, temperatures, and pressures. The percent of theoretical density of the resulting compacts was calculated, and Seebeck coefficients and electrical resistivities of these compacts were measured. In general, the best combination of pressing variables for producing low-electrical resistivities and high densities were: Temperatures in excess of $1,000^{\circ} \mathrm{C}$, pressures of 6,000 to $10,000 \mathrm{psi}$, and periods of 20 to $40 \mathrm{~min}$. More than 80 percent of the samples produced under these conditions had greater than 90 percent of theoretical density and low-electrical resistivities. There was little change noted in the measured seebeck coefficients as the density was varied.

The hot-pressed selenides and tellurides although quite dense, were structurally weak and shattered on impact. The selenides were relatively stable in air at room temperature. A slight reaction with oxygen on the selenide sample surface was noted after several hours exposure, however, after several days no additional oxide was found beneath the surface layers. The tellurides, of which UTe was the most active, rapidly disintegrated in air. Electrical measurements on the tellurides were taken immediately after hot pressing.

The various uranium selenide and telluride compounds prepared in this investigation and the conditions employed during hot pressing are presented in table 3. Although five or more samples of the same or nearly the same composition were generally prepared and tested, the data in table 3 were selected from the sample which exhibited the best defined phase and structura 1 characteristics for that particular stoichiometry. The nominal calculated compositions corrected for material losses during the reaction and hotpressing steps are given in terms of a single stoichiometry regardless of the 
number of phases present. The X-ray diffraction and electron-probe microanalyses identify the phases in the experimental materials. In general, the minor phases accounted for 10 percent or less of the material present. Oxide or oxy-phase reflections were absent in a11 but one of the experimental materials. The average percent impurity in all the samples was from 0.05 to 0.2 percent, silicon from the quartz ampoules being the major contaminent.

TABLE 3. - Analyses and sample fabrication data of undoped uranium chalcogenides

\begin{tabular}{|c|c|c|c|c|c|c|}
\hline \multirow{3}{*}{$\begin{array}{c}\text { Nominal } \\
\text { composition }\end{array}$} & \multirow{2}{*}{\multicolumn{2}{|c|}{$\begin{array}{l}\text { X-ray diffraction- } \\
\text { electron probe analysis }\end{array}$}} & \multicolumn{3}{|c|}{ Fabrication data } & \multirow{3}{*}{$\begin{array}{l}\text { Percent of } \\
\text { theoretical } \\
\text { density }\end{array}$} \\
\hline & & & \multirow{2}{*}{$\begin{array}{c}\text { Pressure, } \\
\text { psi }\end{array}$} & \multirow{2}{*}{$\begin{array}{l}\text { Tempera- } \\
\text { ture, }{ }^{\circ} \mathrm{C}\end{array}$} & \multirow{2}{*}{$\begin{array}{l}\text { Time, } \\
\text { min }\end{array}$} & \\
\hline & $\begin{array}{c}\text { Ma jor } \\
\text { compound }(s)\end{array}$ & $\begin{array}{l}\text { Minor } \\
\text { compound }\end{array}$ & & & & \\
\hline $\mathrm{USe}_{1} . \circ 3 \cdots$ & USe & $\mathrm{U}_{2} \mathrm{Se}_{3}$ & 7,200 & 1,007 & 30 & 91 \\
\hline $\mathrm{USe}_{1.42} \ldots$ & $\mathrm{U}_{2} \mathrm{Se}_{3}$ & $\mathrm{U}$ & 7,300 & 976 & 25 & 85 \\
\hline USe $_{1}, 60 \cdots$ & $\mathrm{U}_{3} \mathrm{Se}_{5}$ & $\mathrm{U}$ & 7,200 & 1,044 & 20 & 97 \\
\hline $\mathrm{USe}_{1.54} \ldots$ & $\mathrm{U}_{3} \mathrm{Se}_{5}, \mathrm{U}_{2} \mathrm{Se}_{3}$ & - & 7,200 & 1,019 & 20 & 91 \\
\hline $\mathrm{USe}_{0.97} \cdots$ & UOSe & $\mathrm{U}_{3} \mathrm{Se}_{5}$ & 9,000 & 1,059 & 30 & 98 \\
\hline $\mathrm{UTe}_{0.99} \cdots$ & UTe & $\mathrm{U}_{3} \mathrm{Te}_{4}$ & 6,500 & 965 & 20 & 93 \\
\hline $\mathrm{UTe}_{1} .10 \cdots$ & $\mathrm{UTe}, \mathrm{U}_{3} \mathrm{Te}_{4}$ & $\mathrm{U}$ & 7,200 & 1,050 & 20 & 97 \\
\hline $\mathrm{UTe}_{1.34} \ldots$ & $\mathrm{U}_{3} \mathrm{Te}_{4}$ & UTe & 7,200 & 1,046 & 30 & 88 \\
\hline $\mathrm{UTe}_{1.47} \ldots$ & $\mathrm{U}_{2} \mathrm{Te}_{3}$ & $\mathrm{UTe}_{2}$ & 7,200 & 1,027 & 25 & 89 \\
\hline
\end{tabular}

The minor phase materials were quite stable, and their concentrations were not significantly altered after long periods at $1,000^{\circ} \mathrm{C}$. The measured diffusion rates in a selenium-uranium diffusion couple indicated that diffusion in the selenides and in uranium was very slow at $1,000^{\circ} \mathrm{C}$ so that the formation of a completely homogenous material was improbable with the processing methods and temperatures employed in this investigation. Although extremely long periods at higher temperatures might have reduced the amount of second phase to less than 1 percent, melting in inert containers with accurate control of the uranium and chalcogen concentrations would be preferred for producing homogeneous materials if the impurities could be held at a low level. The experimental materials were not subjected to extensive crystallization procedures prior to electrical property measurements, because slight differences in phase concentrations did not alter significantly the value of the measured parameters.

\section{Uranium Selenides}

Al1 the uranium selenide powder patterns had a few weak unidentified reflections in addition to the strong reflections characteristic of the particular compound. The nominal composition USe $\mathrm{U}_{.54}$ was two phase and consisted of approximately equal concentrations of $\mathrm{U}_{3} \mathrm{Se}_{5}$ and $\mathrm{U}_{2} \mathrm{Se}_{3}$. The $\mathrm{U}_{3} \mathrm{Se}_{4}$ phase reported by Knodadad (11) was not found in this investigation. Compounds with 


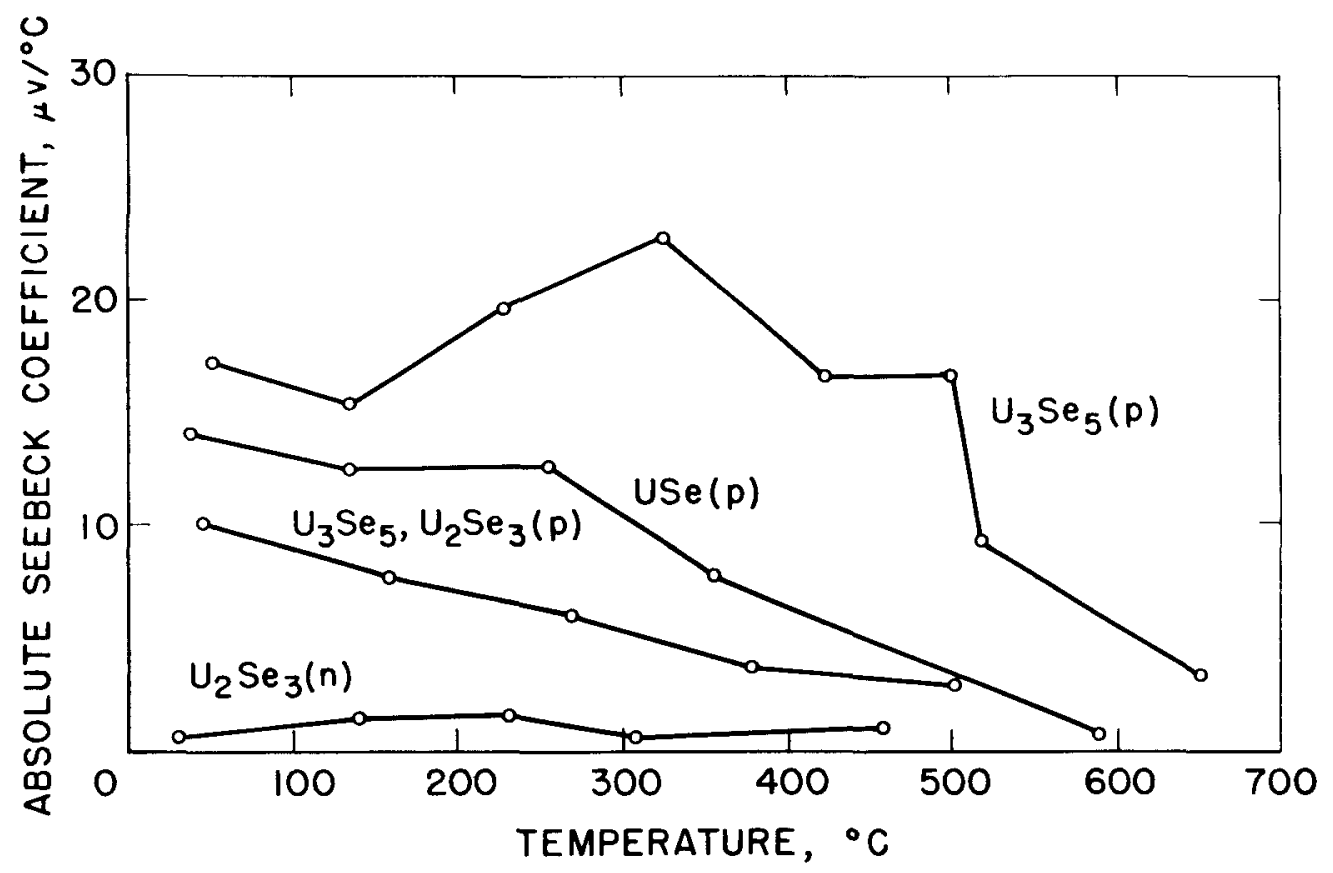

FIGURE 5. - Absolute Se ebeck Coefficient of the Uranium Selenides.

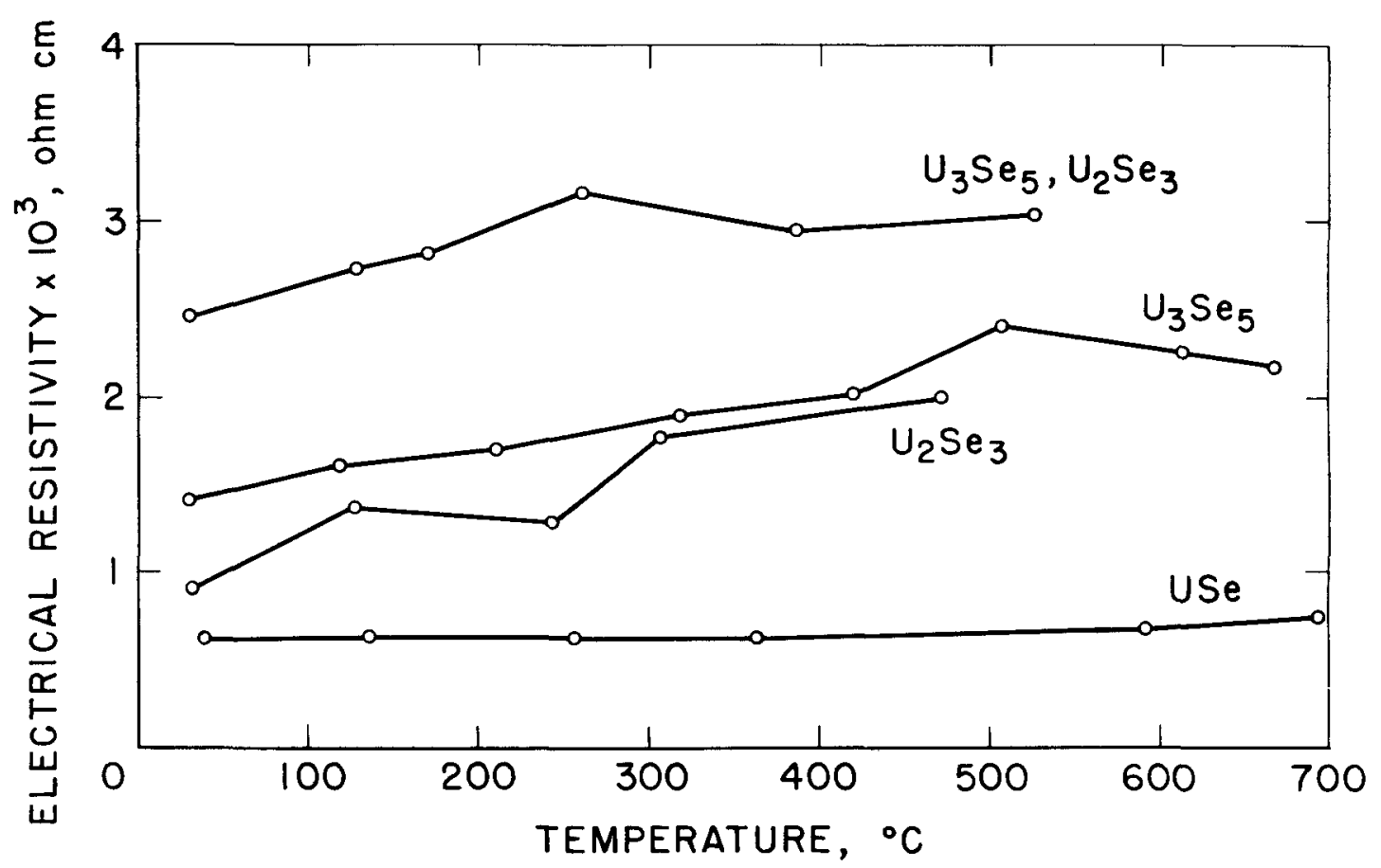

FIGURE 6. - Electrical Resistivity of the Uranium Selenides.

stoichiometric ratios greater than 1:1.67 were not prepared because of their tendency to evolve chalcogen vapor above $400^{\circ} \mathrm{C}$ thus precluding their use in high-temperature thermoelectric devices. The UOSe material was accidentally 


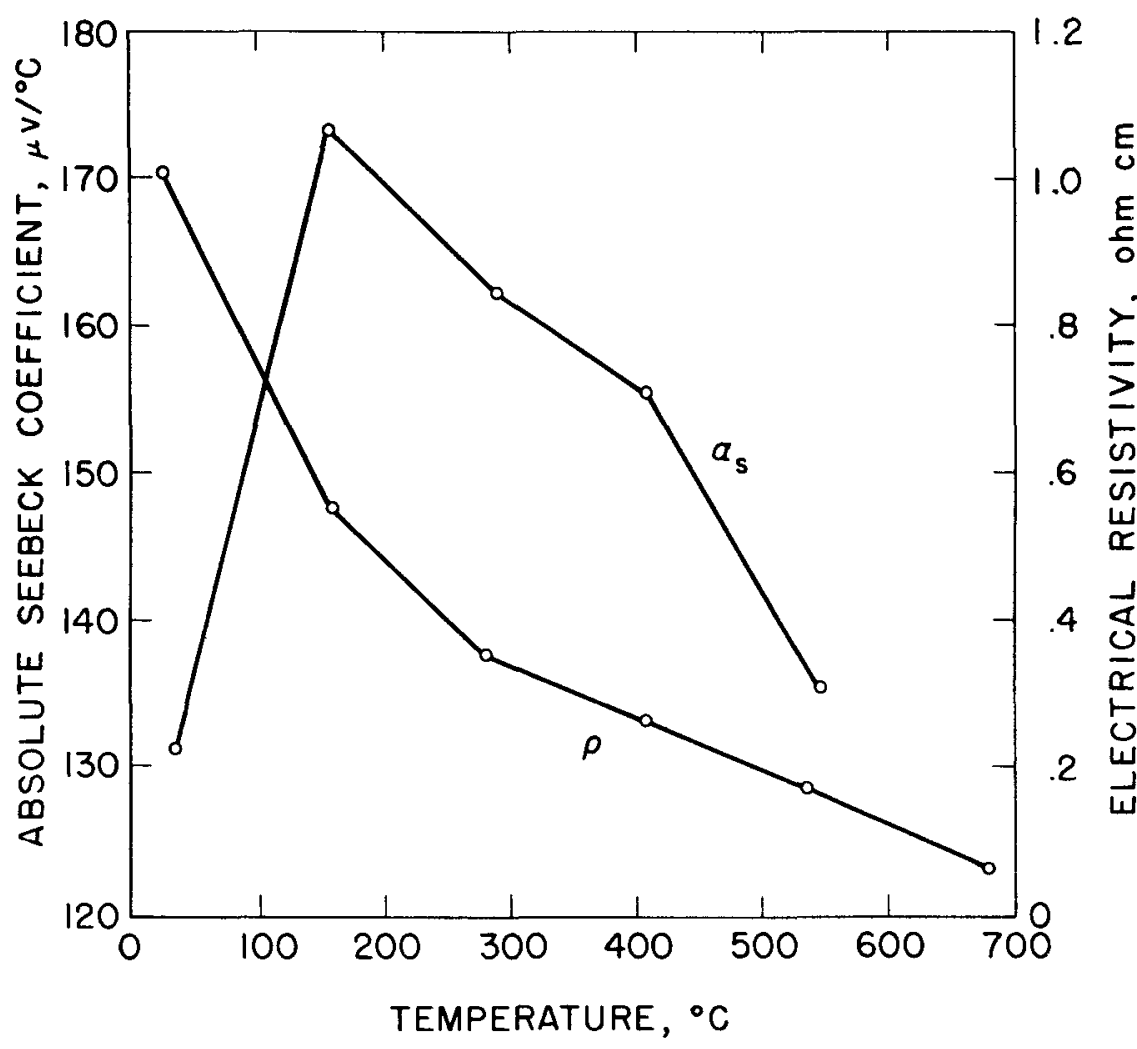

FIGURE 7. - Absolute Seebeck Coefficient and Electrical Resistivity of Uranium Oxyselenide. prepared and is included here because of its interesting properties.

The results of the thermoelectric property investigations of the uranium selenides are plotted in figures 5 and 6 ; similar data for UOSe are in figure 7 . The type of conduction, $\mathrm{n}$ or $\mathrm{p}$, is indicated in parentheses in figure 5. The lines drawn on each curve merely connect the measured points for a particular compound and do not indicate trends in the experimental data. The most homogeneous materials with the lowest impurity contents were used for these measurements;

analyses and fabrication data are given in table 3 . Semimetallic conduction properties were evidenced by the decrease in Seebeck coefficient at higher temperatures and by the positive temperature coefficients of resistivity. The uranium selenides were $\mathrm{p}$-type conductors with the exception of $\mathrm{U}_{2} \mathrm{Se}_{3}$, which was a weak n-type conductor. Although the low-electrical resistivities were quite favorable for practical thermoelectric applications, the low Seebeck coefficients would make the figure of merit prohibitively low for serious consideration even if values of $k$ of 0.01 watt $/ \mathrm{cm}^{\circ} \mathrm{C}$ or less could be assumed. Measurements on completely single-phase material would probably be slightly higher; however, the change in the power factor, $\alpha^{2} / \rho$ would be small. The highest value of $\alpha^{2} / \rho$ was $0.3 \times 10^{-6}$ watts $/ \mathrm{cm}^{\circ} c^{2}$ for the USe sample at room temperature. The electrical properties of the UOSe sample placed it in the semiconducting range, however, $\alpha^{2} / \rho$ at $160^{\circ} \mathrm{C}$ was only $0.5 \times 10^{-7}$ watts $/ \mathrm{cm}^{\circ} \mathrm{C}^{2}$ because of its high electrical resistivity.

Because the selenides appeared to be semimetallic conductors, high-chargecarrier concentrations must have been in evidence which presumedly led to degeneracy. Although the origin of this large concentration of free carriers is unknown, any model of the conduction processes in the U-Se compounds would have to assign some importance to unsatisfied bonds or to energy band overlap if covalent bonding exists. A model based on nonstoichiometry would be unlikely for these compounds because the Seebeck coefficients and electrical resistivities did not appear to be significantly altered by small changes in 
stoichiometry. Measurements on completely single-phase material at the exact stoichiometry would not therefore be expected to yield thermoelectric properties significantly different from those measured. If the p-type conductivity of USe and $\mathrm{U}_{3} \mathrm{Se}_{5}$ is due to unsatisfied bonds it probably arises from the promotion of electrons from the filled uranium s shells to $f$ and $d$ shells to satisfy the demands of the U-Se bonding systems. The ionization of shallow electrons would create holes in the electronic substructure of the lattice which would be free to conduct, thus leading to the p-type conductivity. Because the electron requirement of the selenium $4 \mathrm{p}$ she11 is satisfied by the U-Se bond, elevation of additional electrons from lower lying selenium orbitals is not possible. Of interest is the weak n-type conductivity of the $\mathrm{U}_{2} \mathrm{Se}_{3}$ samples; probably this is the result of overlapping energy bands.

Uranium Tellurides

In almost al1 cases, the experimental uranium tellurides could not be completely identified without the aid of the electron-probe X-ray spectrograph. The UTe and $\mathrm{U}_{3} \mathrm{Te}_{4}$ powder patterns were relatively easy to interpret, but at higher $U: T e$ stoichiometries and in the intermediate compositions, weak lines which could not be assigned to any phase were always present. Results from the electron probe indicated that phases with tellurium concentrations just under the stoichiometric composition might be the origin of these lines which are created by a tellurium-deficient lattice. The UTe 1.10 phase was found to consist of approximately equal concentrations of $\mathrm{U}_{3} \mathrm{Te}_{4}$ and $\mathrm{UTe}$. The $\mathrm{U}_{2} \mathrm{Te}_{3}$ sample could not be identified by X-ray diffraction, but required multiple electron-probe microanalyses to establish the composition.

Table 3 lists the analyses and fabrication data on the tellurides and figures 8 and 9 are plots of the thermoelectric-property data versus temperature. The tellurides were semimetallic, $n$-type conductors with the exception of $\mathrm{U}_{2} \mathrm{Te}_{3}$ which was a p-type conductor. Measurements on the $\mathrm{U}_{2} \mathrm{Te}_{3}$ sample were discontinued above $350^{\circ} \mathrm{C}$ because of the slow evolution of tellurium vapor from the sample at the higher temperatures. As with the uranium selenides, $\alpha^{2} / \rho$ for the tellurides was too low for consideration in practical devices. The highest value of $\alpha^{2} / \rho$ for the tellurides was $0.5 \times 10^{-6}$ watts $/ \mathrm{cm}^{0} \mathrm{c}^{2}$ for the UTe sample at $650^{\circ} \mathrm{C}$. Of interest was the $\mathrm{U}_{2} \mathrm{Te}_{3}$ sample with $\alpha^{2} / \mathrm{p}$ equal to $0.4 \times 10^{-6}$ watts $/ \mathrm{cm}^{\circ} \mathrm{C}^{2}$ at $350^{\circ} \mathrm{C}$ which might be increased at higher temperatures if suitable encapsulation could be found.

As with the uranium selenides, a conduction model based on nonstoichiometry does not seem applicable for the tellurides. Electrons in excess of those needed for bonding or energy band overlap seem to be the most reasonable physical interpretation of the UTe and $\mathrm{U}_{3} \mathrm{Te}_{4}$ behavior. The low values of the electrical parameters at low temperatures indicate high concentrations of electrons in a fairly high mobility conduction band. This would indicate that the Fermi energy level which governs the occupation of electron states approaches the conduction band or enters it. Because the uranium and tellurium subshells are only partially filled, electrons could be promoted to the conduction band where the semiconductor would become wholly or partially degenerate with an electron energy distribution similar to that of a metal. The increase in Seebeck coefficient with temperature for most of the samples is probably the result of the electronic thermal energy, $k T$, becoming 


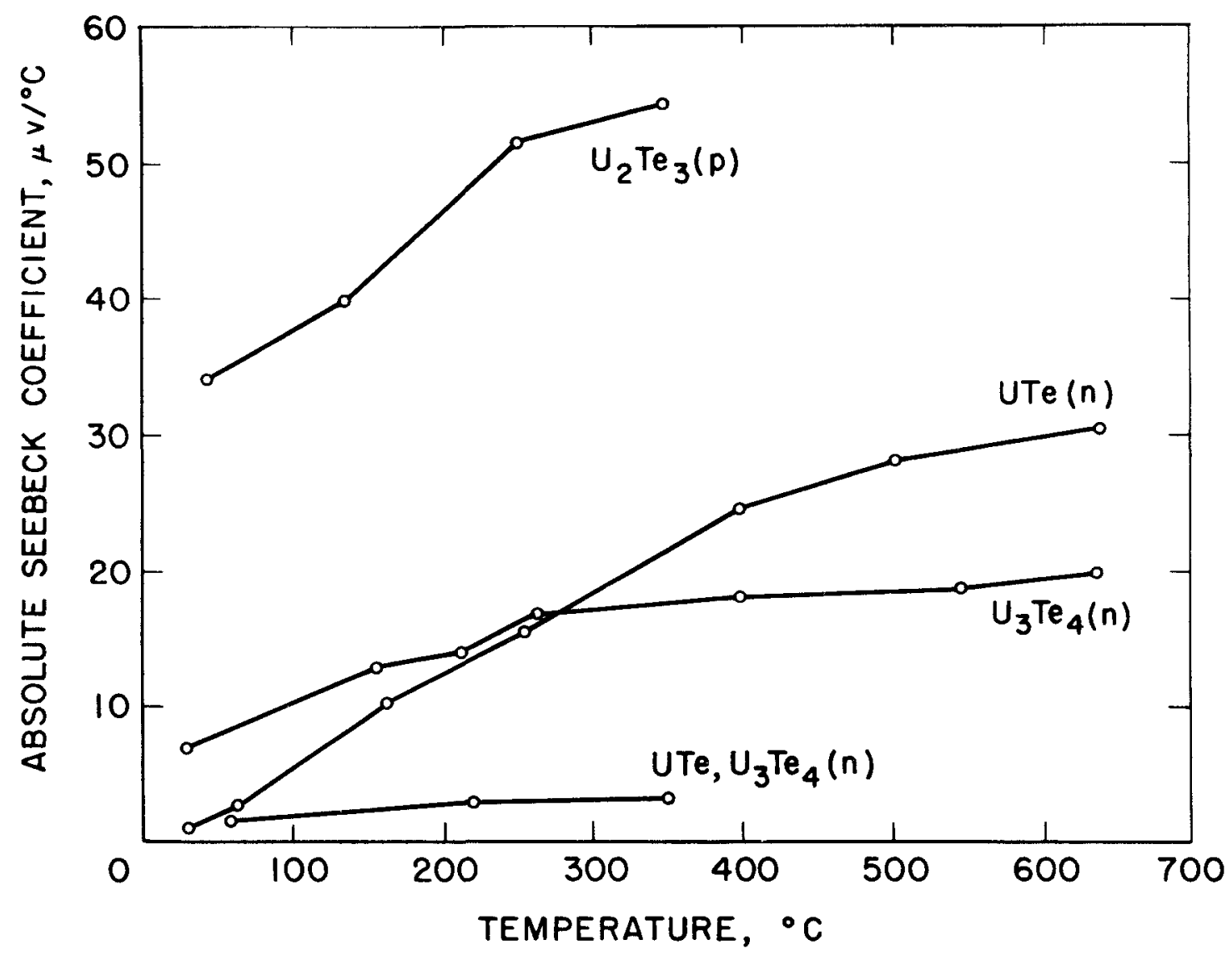

FIGURE 8. - Absolute Seebeck Coefficient of the Uranium Tellurides.

comparable with the gap energy as the Fermi level shifts toward the valence band. The downward movement of the Fermi level decreases the probability that any state in the conduction band is occupied by an electron so that the electron distribution becomes less degenerate and normal semiconductor behavior results. The $\mathrm{U}_{2} \mathrm{Te}_{3}$ p-type conductivity similar to that of several of the uranium selenides is probably also due to unsatisfied electron bonds and the promotion of lower lying electrons to satisfy the U-Te bond.

\section{Doped Uranium Monocha lcogenides}

Several attempts were made during this investigation to improve the Seebeck coefficients of the uranium monochalcogenides by doping. Sma11 increases in electrical resistivity could be tolerated if higher Seebeck coefficients resulted, inasmuch as the undoped sample resistivities were quite low. The monochalcogenides, USe, and UTe were investigated because they appeared to have the most promising undoped properties. The Group Va elements (As, $\mathrm{Sb}$, and $\mathrm{Bi}$ ) with five valence electrons were chosen for doping the uranium monoselenides in an effort to fill the electron deficiency in the U-Se bonds and possibly to increase the covalency of the compound. The elements In, $\mathrm{T} 1$, and $\mathrm{Zn}$ with less than four valence electrons were added to the uranium 


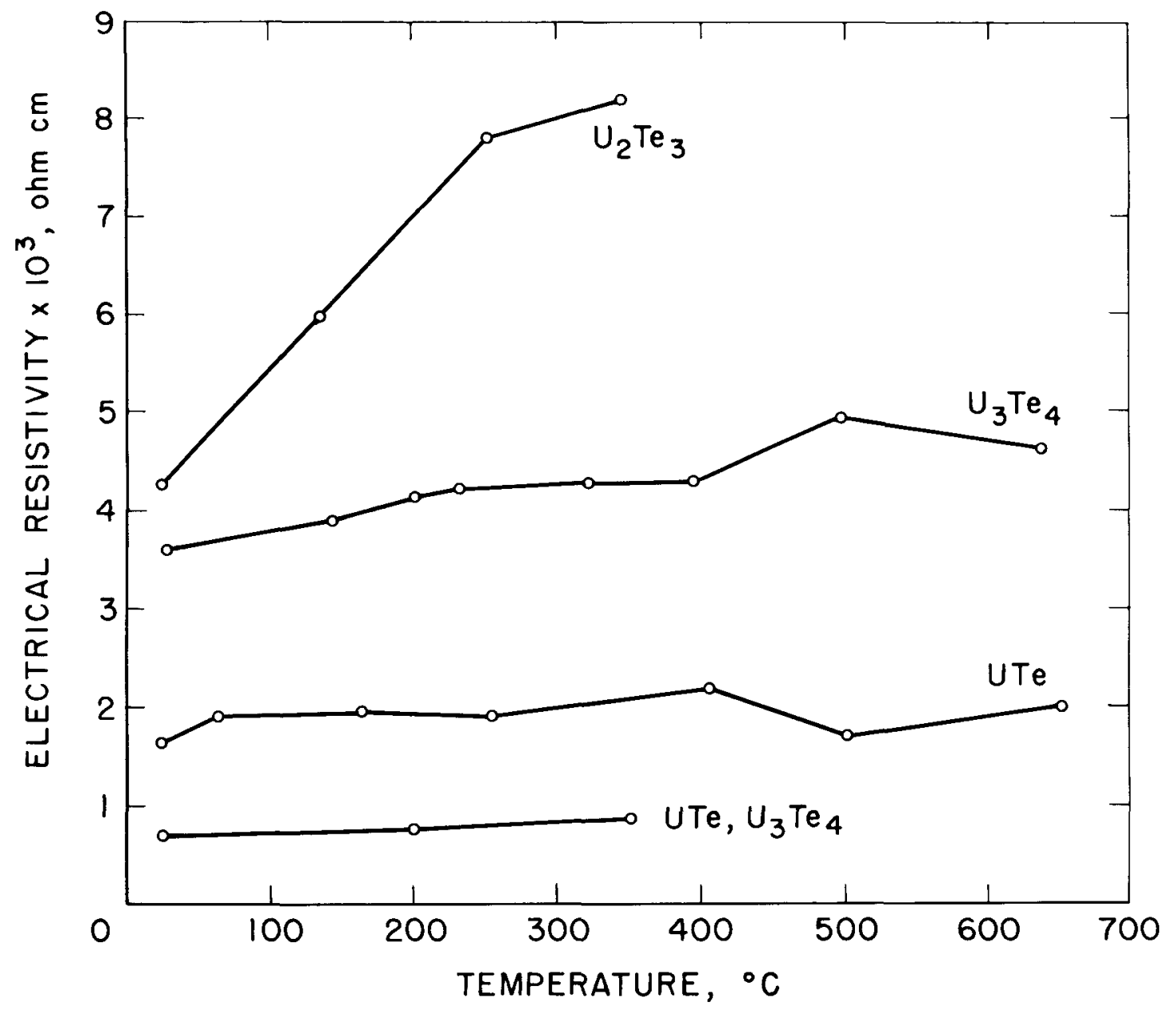

FIGURE 9. - Electrical Resistivity of the Uranium Tellurides.

monotellurides in attempts to reduce degeneracy by immobilizing some of the conduction electrons in metal-nonmeta 1 bonds. No compound additions were made.

The doped samples containing from 0.5 to 4 percent of the doping agents were prepared and tested in the same manner as the undoped materials. X*ray diffraction identification of these materials was difficult, however, electron probe microanalyses allowed fairly accurate compound determinations. Random determinations of the Seebeck coefficient and electrical resistivity were made and compared with the undoped values to assess the overall effect of doping. In general for measurements at the same temperature, the Seebeck coefficients of the undoped uranium monochalcogenides were increased by factors of from 2 to 6. The corresponding increases in electrical resistivity, however, were as high as one hundred times the undoped value, so that the net increase in $\alpha^{2} / \rho$ for the doped materials was slight. A11 the doped monochalcogenides were p-type conductors. The change in conduction mechanism for the tellurides indicates that doping was effective in eliminating the large concentration of 
conduction electrons, probably by the formation of localized negative charges around metal-nonmeta 1 bonds.

Improved purities, compound doping, and doping with a larger number of impurities with wide ranges of concentrations might yield materials with properties improved over those measured, however, values of $\alpha^{2} / \rho$ in excess of $10^{-6}$ watts $/ \mathrm{cm}^{\circ} \mathrm{C}^{2}$ appear improbable for the uranium chalcogenides.

\section{CONCLUSIONS}

Depleted uranium chalcogenides with fairly uniform compositions can be produced by vapor diffusion reaction techniques. Long periods at high temperatures eliminate most of the concentration gradients, however, impurity build-up from the container makes this method of producing completely homogeneous chalcogenide materials unsatisfactory. Melting in inert containers would be preferred if impurities could be minimized and suitable grain refinement obtained.

Many of the chalcogenide compounds exhibit complex phase relationships making it difficult to obtain accurate X-ray diffraction identifications. Electron probe microanalytical techniques when used in conjunction with $\mathrm{X}$-ray diffraction are successful in identifying these experimental materials, but such methods are often relatively expensive and time consuming.

The undoped uranium chalcogenides are semimetallic conductors exhibiting low Seebeck coefficients and electrical resistivities. Values of $\alpha^{2} / \rho$ in the figure of merit for the uranium chalcogenides are prohibitively low for consideration in practical thermoelectric devices. The best measured values of $\alpha^{2} / \rho$ for the undoped uranium selenides and tellurides are $0.3 \times 10^{-6}$ and $0.5 \times 10^{-6}$ watts $/ \mathrm{cm}^{\circ} \mathrm{C}^{2}$, respectively for the USe and UTe samples as compared to commercial thermoelements with $\alpha^{2} / \rho$ values of $10^{-4}$ to $10^{-5}$ watts $/ \mathrm{xm}^{\circ} \mathrm{C}^{2}$.

The thermoelectric properties of the uranium chalcogenides are not dependent on slight changes in stoichiometry; thus small compositional variations do not drastically alter the values of the Seebeck coefficient and electrical resistivity. The degenerate characteristics of the uranium chalcogenides are best explained by conduction processes based on unsatisfied bonds or energyband overlap.

Doping is successful in increasing the Seebeck coefficient of the uranium monochalcogenides, however, $\alpha^{2} / \rho$ is not significantly improved because of the corresponding increases in electrical resistivity. Additional doping experiments might produce a material with $\alpha^{2} / \rho$ as high as $10^{-6}$ watts $/ \mathrm{cm}^{-}{ }^{\circ} \mathrm{C}^{2}$; however, further increases in this value are unlikely for the depleted uranium chalcogenides. 


\section{REFERENCES}

1. Blankenship, W. P. Preparation and Preliminary Thermoelectric Evaluation of the Uranium Chalcogenides. Westinghouse Elec. Corp., WCAP-1866, October $1961,40 \mathrm{pp}$.

2. Brown, J. D., and Others. Design, Construction and Evaluation of an Electron Probe X-ray Spectrograph. BuMines Rept. of Inv. 6111, 1962, $30 \mathrm{pp}$.

3. Burke, J. E., and C. S. Smith. The Formation of Uranium Hydrides. J. Am. Chem. Soc., v. 69, 1947, pp. 2500-2503.

4. Driggs, F. H. Preparation of Metal Hydrides. U.S. Pat. 1,835,024, Dec. 8, 1931.

5. Egli, Paul H. Thermoelectricity. John Wiley \& Sons, Inc., New York, 1960, pp. 233-269.

6. Ferro, Reccardo. On Some Selenium and Tellurium Compounds of Uranium. A.E.R.E. Trans 1. 11/3/5/440, 1954, 6 pp.

7. Gronvold, F., and Others. Technical Report of the Composition, Structure, and Magnetic Properties of Some Uranium Chalcogenides. Chem. Inst., Univ. of Oslo, ARL-62-427, part 2, Mar. 31, 1962, 63 pp.

8. Heikes, Robert R., and Roland W. Ure. Thermoelectricity Science and Engineering. Interscience Publishers, New York, 1961, 576 pp.

9. Joffe, A. F. Semiconductor Thermoelements and Thermoelectric Cooling. Infosearch, Ltd., London, 1957, 184 pp.

10. Jordan, D. B. High Temperature Semiconducting Compounds for Thermoelectric Power Generation. Electro-Optical Systems, Inc., EOS-1592, Jan. 15, 1962, 39 pp. (Available as AD 277,002.)

11. Khodadad, Parviz. Compounds of the Uranium-Selenium System, Preparation, Physical and Chemical Properties. Soc. Chim. France, Bul1. Nos. 1-6, January 1961, pp. 133-136.

12. Matson, L. K., and Others. Preparation and Properties of Some Uranium Selenides and Tellurides. J. Inorg. Nuc. Chem., v. 25, 1963, pp. 795-800.

13. Pearson, W. B. Handbook of Lattice Spacing and Structure of Metals. Pergamon Press, New York, 1958, pp. 213-216.

14. Warren, I. H. The Development of Semiconductor Uses for Uranium Compounds. Canadian Res. Foundation, Prog. Rept. Nos. 2 through 5, January 1962. 